\title{
How to Improve Therapeutic Ratio in Radiotherapy of HCC
}

\author{
Chiao-Ling Tsaia,b Feng-Ming Hsu ${ }^{a} \quad$ Jason Chia-Hsien Cheng ${ }^{a, c}$ \\ aDivision of Radiation Oncology, Department of Oncology, National Taiwan University Hospital, \\ ${ }^{b}$ Graduate Institute of Clinical Medicine, National Taiwan University College of Medicine, 'Graduate \\ Institute of Oncology, National Taiwan University College of Medicine, Taipei, Taiwan (ROC)
}

\section{Key Words}

Biomarkers · Hepatocellular carcinoma - Molecular targeted agents · Radiation therapy

\begin{abstract}
Background: During the past two decades, external-beam radiation technology has substantially changed from traditional two-dimensional to conformal three-dimensional to intensity-modulated planning and stereotactic body radiotherapy (SBRT). Summary: Modern techniques of radiotherapy (RT) are highly focused and capable of delivering an ablative dose to targeted hepatocellular carcinoma (HCC) tumors. SBRT is an option for selected patients with limited tumor volume and non-eligibility for other invasive treatments. Moreover, RT combined with a radiation sensitizer (RS) to increase the therapeutic ratio has shown promising results in select studies, prompting further investigation of this combination. With the undetermined role of RT in treatment guidelines and variation in patterns of treatment failure after RT in patient with HCC, useful biomarkers to guide RT decision-making and selection of patients are needed and emerging. Key Message: The objective of this review is to summarize the current RS with SBRT schemes and biomarkers for patient selection used to maximize the effect of RT on HCC.

Copyright (C) 2016 S. Karger AG, Basel
\end{abstract}

\section{Introduction}

Most patients with locally advanced hepatocellular carcinoma (HCC) are not candidates for potentially curative treatment, including surgery and radiofrequency ablation, due to pre-existing liver diseases, co-morbidities, or poor performance status [1]. Aggressive lo- 
cal treatment is justified by the high rate of intrahepatic recurrence in patients undergoing surgery [2], and most of these patients eventually undergo multiple treatments including transarterial chemoembolization (TACE), cryotherapy, microwave ablation, and other ablative techniques. Historically, external beam radiotherapy (EBRT) has been used only for palliative treatment in HCC owing to low hepatic tolerance. Some have proposed the use of stereotactic body radiotherapy (SBRT), with lower fraction number and higher dose intensity, to maintain local control of HCC after surgery [3]. With the advancement of SBRT technology, local tumor radiotherapy (RT) has become more focused with greater sparing of the surrounding tissue [4].

A radiation sensitizer (RS) is a pharmacologic agent that improves the action of RT on target tissue. In a preclinical model, robust evidence has shown the benefit of adding a variety of pharmaceutical agents acting as RSs to EBRT [5]. Theoretically, the cytopathic effect of EBRT is due to breaks in the double-stranded deoxyribonucleic acid (DNA). The most investigated RSs are chemotherapeutic agents, especially DNA base analogs, with analogs of platinum and 5-fluorouracil (5-FU) being among those first tested or used as RSs clinically. Later, molecular targeted agents including inhibitors of phenylbutyrate-derived histone deacetylase (HDAC), Aurora kinase, phosphatidylinositol 3-kinase (PI3K) and other multikinase inhibitors were reported to potentiate the effect of EBRT on HCC [6-9]. Recently, immunotherapeutic approaches have been shown to have advantages in a variety of cancer treatments, and local RT with intratumoral injection of vaccines shown to elicit tumor-specific immune responses [10].

Because HCC treatment options vary and their patterns of failure are unpredictable, useful biomarkers are needed to guide therapeutic strategies. Traditionally, alpha-fetoprotein (AFP) is the most commonly accepted marker of HCC invasiveness. Unfortunately, only $50 \%$ of patients with HCC have detectable AFP [11]. Other potential prognostic or predictive biomarkers including des- $\gamma$-carboxy prothrombin (DCP) and the lens culinaris agglutininreactive fraction of AFP (AFP-L3) have been extensively investigated [12]. However, few biomarkers of RT responsiveness or toxicity in HCC have been documented. Only a few reports have linked angiogenic factors in serum to circulating tumor cells (CTC) in patients with HCC undergoing RT.

In this review, we have summarized the current evidence about SBRT, RSs, and biomarkers to propose new effective RT strategies in HCC.

\section{RT Fractionation}

Due to the high vulnerability of liver to injury by EBRT, its role in conventional HCC treatment is limited. Radiation-induced liver disease (RILD), background liver disease, and possible hepatitis B reactivation after EBRT are key considerations in planning RT for HCC. For many years, liver RT has been limited only to palliation [13]. With the advent of three-dimensional conformal RT (3D-CRT), high doses could be delivered to individual tumors with good sparing of the surrounding parenchyma. With the help of normal tissue complication probability models to predict RILD and dose-limiting hepatotoxicity, the use of EBRT in HCC has been re-established [14]. The French phase II RTF-1 trial showed promising results of using 3D-CRT with 66 Gy (2 Gy fractions) for small HCC. In selected patients with Child-Pugh class A/B cirrhosis and small-size HCC ( 1 nodule $\leq 5 \mathrm{~cm}$, or 2 nodules $\leq 3 \mathrm{~cm}$ ) unsuitable for curative treatment, there was a complete response in $80 \%$ of patients [15]. In the era of 3D-CRT, a retrospective cohort study of 398 patients with HCC from 10 Korean institutions found that higher RT dose (i.e., biologically effective dose [BED] $>53.1 \mathrm{~Gy}_{10}$ ) improved 
prognosis [16]. A study from Japan reported that a total RT dose $>50.4$ Gy increased survival [17]. Hence, subsequent studies have been focused on alternative fractionation schemes to increase the RT effect.

With the aid of immobilization devices, respiratory control systems, and image guidance systems, it was discovered that hypofractionated ablative doses can be safely used with SBRT. In a 1995 pioneer study of SBRT in liver tumors reported by Blomgren et al. [18], 11 of 42 HCC lesions received 15-45 Gy in 1-3 fractions. Two of the tumors responded completely. However, two of the eight patients with HCC with large tumors (target volumes 57-633 ml) died 2-20 days after treatment due to deterioration of liver cirrhosis. Subsequent SBRT studies have examined considerably different schemes (table 1).

\section{Retrospective Studies of SBRT to HCC}

Choi et al. analyzed the data from 20 patients with HCC treated with SBRT using 50 Gy in 5 or 10 fractions; most patients had Child-Pugh A cirrhosis. After a median follow-up of 23 months, the response rate was $80 \%$, and median survival was 20 months [19]. Kwon et al. reported on 42 patients with HCC with liver target volumes (less than $100 \mathrm{ml}$ ) treated with 30-39 Gy in 3 fractions. The in-field complete response was $59.6 \%$ and the local control rate at 2 years was $72 \%$ [20]. Seo et al. reviewed the data from 38 patients with HCC of less than $10 \mathrm{~cm}$ treated with SBRT (33-57 Gy in 3-4 fractions) as a salvage treatment. At three months after SBRT, the local response rate was $63 \%$ based on computed tomography scan images. A high radiation dose was independently associated with survival. Only one $(2.7 \%)$ patient experienced a serious adverse event (i.e., grade 3 dermatitis) [21]. Louis et al. reported on 25 patients with HCC treated with cyberknife SBRT using 45 Gy in 3 fractions. Grade 3 acute toxicities developed in two (8\%) patients, and the 2-year local control rate was 95\% [22].

Andolino et al. reviewed the data from 60 patients with HCC and Child-Pugh A/B treated with SBRT using 24-48 Gy in 3-5 fractions delivered to liver tumors smaller than $6 \mathrm{~cm}$. The 2-year local control rate was $87 \%$. Of the 21 (35\%) patients who experienced grade 3 hematologic/hepatic toxicity, 17 had preexisting grade 2 hematologic/hepatic toxicity [23]. A review by Huang et al. of 36 cases of recurrent HCC in patients undergoing cyberknife SBRT with 25-48 Gy in 4-5 fractions identified a grade 3 gastric ulcer in one $(2.8 \%)$ patient and revealed a 2-year local control rate of 75\% [24]. Bae et al. reported on 35 Barcelona Clinic Liver Cancer stage $C$ and Child-Pugh A patients with HCC receiving SBRT with 30-60 Gy in 3-5 fractions. Eight (23\%) patients had main portal vein tumor thrombosis. The median PTV (planning target volume) and SBRT dose were $131 \mathrm{ml}$ (range: 21-2189 ml) and 45 Gy in 3-5 fractions (range: 30-60 Gy). Eight (23\%) and two (5.7\%) patients experienced grade 3 hematologic/hepatic toxicity and grade 4 gastric or colonic perforation, respectively. The 1 - and 3 -year local control rates were $69 \%$ and $51 \%$, respectively. SBRT dose of BED $\geq 80 \mathrm{~Gy}_{10}$ was a significant prognostic factor for survival [25].

\section{Prospective Trials of SBRT to HCC}

Mendez Romero et al. reported the outcomes of a phase I/II trial of SBRT in four patients with HCC (tumor size $<4 \mathrm{~cm}$ ) and no cirrhosis who received an SBRT dose of 37.5 Gy in 3 fractions and in four patients with HCC (tumor size $\geq 4 \mathrm{~cm}$ ) and cirrhosis who received 25 Gy in 5 fractions or 30 Gy in 3 fractions. The crude local control rate and actuarial overall survival (OS) rate at one year were $82 \%$ and $75 \%$, respectively. However, a higher than grade 3 toxicity was noted in one patient with Child-Pugh B who developed liver failure with a fatal infection [26].

A phase I study at Princess Margaret Hospital included 31 patients with unresectable Child-Pugh A HCC. The median dose of SBRT was 36.0 Gy (range: 24-54 Gy) in 6 fractions. 
Within the first three months, eight patients developed grade 3 elevated liver enzymes. The 1-year survival rate was $48 \%$, and the overall response rate was $49 \%$ [27].

Bujold et al. pooled the results of one phase I/II study and one phase II trial using SBRT in patients with HCC unsuitable for standard locoregional therapies. A total of 102 patients were enrolled and SBRT dose was 24-54 Gy in 6 fractions. More than grade 3 toxicity was noted in 27 (30\%) patients. Local control rate at 1 year was $87 \%$. Factors associated with better survival by multivariate analysis were the absence of tumor vascular thrombosis and inclusion in the phase II trial (with limitation on HCC lesion number $[\leq 5 \mathrm{~cm}]$ and maximal lesion dimension [ $<15 \mathrm{~cm}$ ]) [3]. A contemporary phase I to II trial conducted at Indiana University Hospital in 26 non-surgical candidate patients with HCC (tumor number $\leq 3$, sum diameters $\leq 6 \mathrm{~cm}$ ) receiving a median SBRT dose of 42 Gy (range: 24-48 Gy) in 3-5 fractions found an overall response rate of 73\% and 1-year survival rate of 77\% [4].

\section{Charged Particle Therapy (CPT)}

CPTs, including proton beam therapy (PBT) and carbon ion therapy (C-ion RT), have the unique properties of rapid dose fall-off beyond the Bragg peak and of higher relative biological effectiveness compared with photon therapy. Thus, CPTs have been regarded as a more tumor-specific treatment than traditional photon RT.

Prospective studies with CPT in HCC are limited with few phase I to II trials. Two prospective trials with PBT and one trial with C-ion RT have been published in the recent decade. In one study from Japan, 51 patients received PBT with 66 GyE (gray equivalent) in 10 fractions. The 5-year OS of $38.7 \%$ and local control of $87.8 \%$ were reported [28]. Another study was published by Bush et al. from Loma Linda University Medical Center. In the phase II study, 76 patients were treated by PBT with a dose scheme of 63 GyE in 15 fractions. The median OS times for Child-Pugh class A, B, and C were 34 months, 13 months, and 12 months, respectively. With PBT as a bridging treatment, 18 patients subsequently underwent liver transplantation with a 3-year survival rate of 70\% [29].

In the dose-escalation trial of C-ion RT by Kato et al., a promising local control after this therapy for 24 patients was reported. The OS rates were $92 \%, 50 \%$, and $25 \%$ and local control rates were $92 \%, 81 \%$, and $81 \%$ at 1,3 , and 5 years, respectively. No dose-limiting toxicity was observed with the dose escalation from 49.5 to 79.5 GyE in 15 fractions. They suggested a dose of $72 \mathrm{GyE}$ for an optimal benefit between high local control rate and low probability of grade III toxicity [30] (table 2).

However, CPTs have not been directly compared to photon RT. Qi et al. conducted a meta-analysis to compare treatment efficacy between CPT and photon RT in patients with HCC. Although they found that CPT (compared with conventional RT [CRT]) significantly improved OS, progression-free survival, and local control at longest follow-up, the irradiated liver tumors were significantly larger and the RT doses were significantly lower in patients treated with CRT than in patients treated with CPT. Moreover, the survival and local control rates were similar between the CPT and SBRT groups. Furthermore, the rate of more than grade 3 toxicity was lower in patients treated with CPT than in patients treated with CRT or SBRT [31].

\section{RS}

The advances in RT technology make possible delivery of an ablative dose to HCC while protecting surrounding non-cancerous tissue. A RS can augment the anti-HCC effect of RT, which damages the DNA of neoplastic cells leading to their death. The pyrimidine analog, 


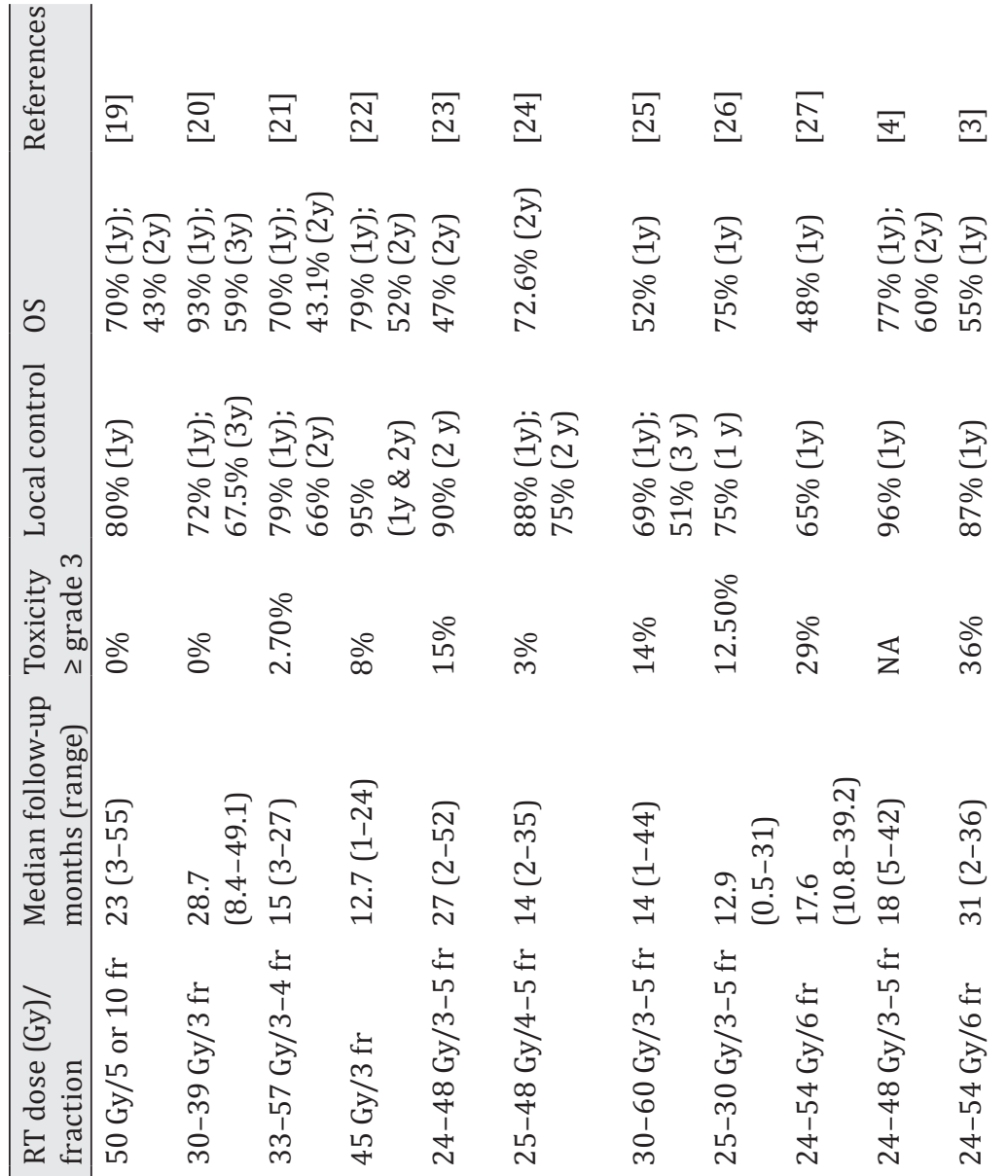

$\frac{5}{60}$

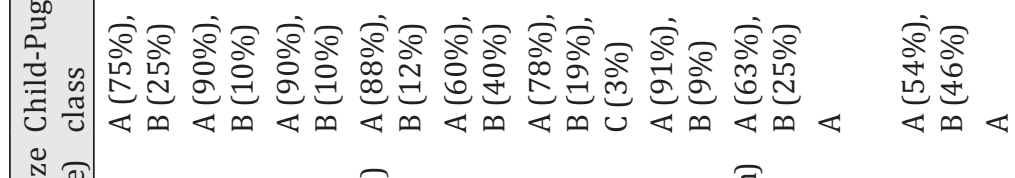

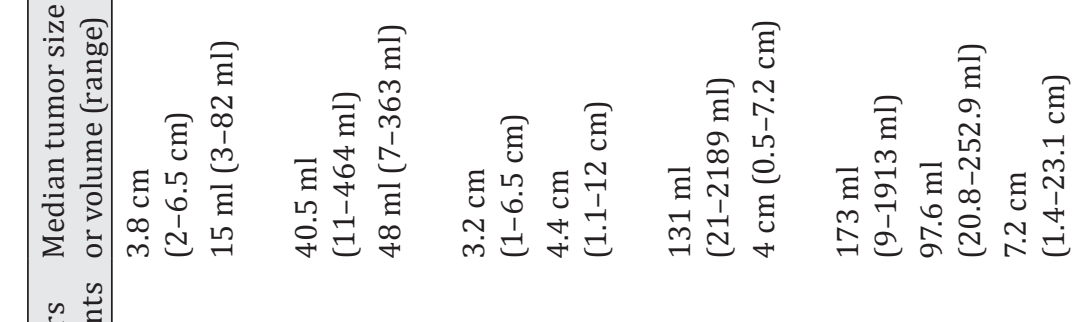

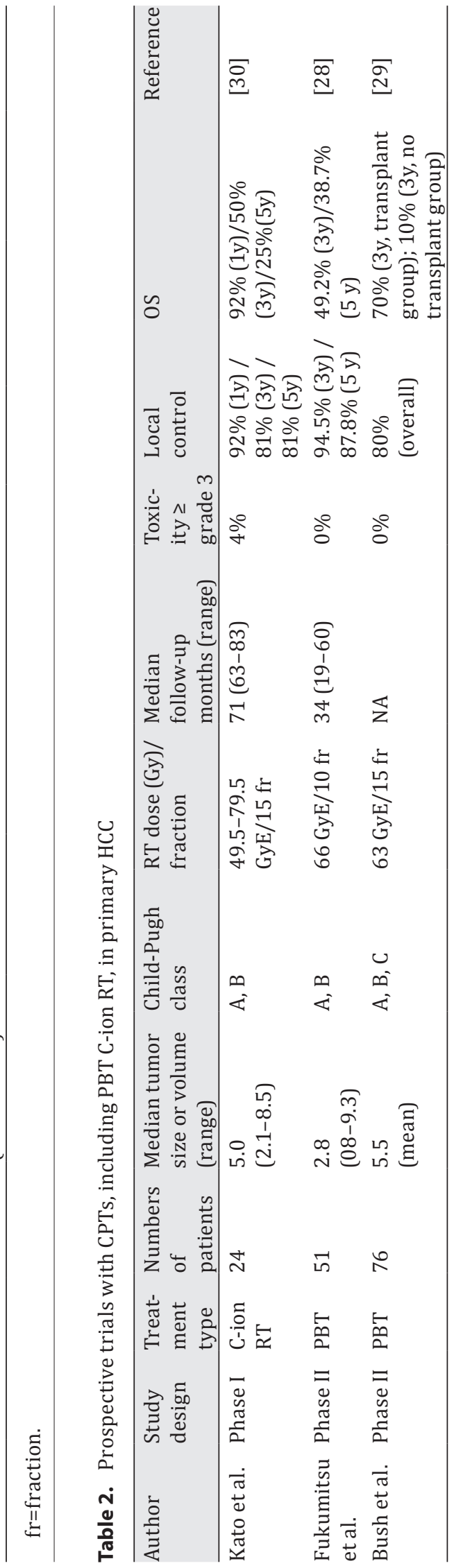


Table 3. Preclinical study with novel molecular targeted therapies as RSs in HCC

\begin{tabular}{|c|c|c|c|c|}
\hline Agent & Target & Cell Line & Animal Model & References \\
\hline AR-42 & HDAC inhibitors & Huh-7 and PLC-5 & $\begin{array}{l}\text { Ectopic and orthotopic } \\
\text { xenografts }\end{array}$ & [6] \\
\hline VE-465 & $\begin{array}{l}\text { Aurora kinase } \\
\text { inhibitor }\end{array}$ & Huh-7 and PLC-5 & $\begin{array}{l}\text { Ectopic and orthotopic } \\
\text { xenografts }\end{array}$ & {$[7]$} \\
\hline BKM120 & PI3K inhibitor & Huh-7 and BNL & Ectopic xenografts & {$[8]$} \\
\hline SC-59 & $\begin{array}{l}\text { Sorafenib derivative } \\
\text { and SHP-1 agonist }\end{array}$ & $\begin{array}{l}\text { SK-Hep1, Hep3B, and } \\
\text { Huh-7 }\end{array}$ & Ectopic xenografts & {$[9]$} \\
\hline ANI & PARP-1 inhibitor & HepG2 & In vitro study & [42] \\
\hline Sorafenib & $\begin{array}{l}\text { Multiple kinases } \\
\text { inhibitor }\end{array}$ & $\begin{array}{l}\text { PLC-5, Huh-7, Sk-Hep1, } \\
\text { and Hep3B }\end{array}$ & Ectopic xenografts & [37] \\
\hline Sorafenib & $\begin{array}{l}\text { Multiple kinases } \\
\text { inhibitor }\end{array}$ & $\begin{array}{l}\text { SMMC-7721 and } \\
\text { SK-Hep1 }\end{array}$ & Ectopic xenografts & [38] \\
\hline
\end{tabular}

Huh-7=human hepatoma cell line; PLC-5=PLC/PRF/5; BNL=BNL CL.2; SK-Hep1=an immortal, human cell line derived from the ascetic fluid of a patient with adenocarcinoma of the live; Hep3B=Hep 3B2.1-7; HepG2=liver hepatocellular cells; SMMC-7721=human hepatocellular carcinoma cell line; PARP-1=Poly (ADP-ribose) polymerase-1.

5-FU was an initial RS used in cancer treatment. 5-FU acts as an antimetabolite that irreversibly inhibits thymidylate synthase by competitive binding during DNA biosynthesis. The efficacy of using drugs concurrently with RT to potentiate radiation effects was first established by Heidelberger in 1958 who showed that concurrent 5-FU and RT acted synergistically in a preclinical sarcoma xenograft model [32]. The combination of chemotherapy with liver RT has previously been used in liver metastasis treatment. Traditionally, whole liver RT with 20-30 Gy in 10-15 fractions has been used for palliation of painful liver metastasis or primary liver cancer. However, whole liver RT with concomitant intra-arterial 5-FU or its derivatives proved to be only minimally beneficial [33].

Recently, the availability of novel molecular targeted therapies has increased anticancer treatment options. Therapies targeting a specific molecular pathway involved in tumor development and progression are new. Sorafenib (Nexavar $\left.{ }^{\circledR}\right)$ is a multikinase inhibitor that targets the Raf/MAPK/ERK signaling pathway and induces blockade of tumor growth. It also has an anti-angiogenic effect by interfering with the tyrosine kinase of vascular endothelial growth factor receptor [VEGFR]-2, VEGFR-3, and platelet-derived growth factor receptor-b . Both the Raf/MAP/ERK cascade and angiogenic signaling pathways are critical in the pathogenesis of HCC. The demonstration that sorafenib induces apoptosis and inhibits angiogenesis in an HCC model [34] implies the therapeutic potential of sorafenib in HCC.

The results of the Sorafenib Hepatocellular Carcinoma Assessment Randomized Protocol (SHARP) trial found a prolonged survival by sorafenib relative to placebo [35]. Another phase III trial conducted in the Asia-Pacific region also reported a survival benefit in patients with advanced HCC [36]. Subsequently, sorafenib became a salvage treatment in patients with HCC with macrovascular invasion and extrahepatic metastases. In vitro and in vivo studies have shown that sorafenib increases radiation-induced apoptosis by downregulating phosphorylation of signal transducer and activator of transcription 3 (STAT3) [37], and decreased VEGFR-2-dependent angiogenesis by inhibiting radiation-induced activation of VEGF-2 [38] (table 3).

Few clinical studies have been published on sorafenib combined with RT. In a retrospective study in 13 patients with HCC receiving sorafenib and local RT (30-54 Gy) to the main liver tumor, Cha et al. found a response rate of $61 \%$. They also identified the most common 
Table 4. Summary of clinical study using molecular targeted therapies as a RS in HCC

\begin{tabular}{|c|c|c|c|c|c|c|}
\hline Study Type & Agent & $\begin{array}{l}\text { No of } \\
\text { patients }\end{array}$ & RT dose & $\begin{array}{l}\text { Grade } 3 \\
\text { toxicity }\end{array}$ & $\begin{array}{l}\text { Response } \\
\text { rate }\end{array}$ & References \\
\hline Retrospective & $\begin{array}{l}\text { Sorafenib } \\
\text { (800 mg daily) }\end{array}$ & 13 & $\begin{array}{l}30-54 \mathrm{~Gy} / \\
1.8-5 \text { Gy per } \\
\text { fraction }\end{array}$ & $17 \%$ & $61 \%$ & [39] \\
\hline Phase II & $\begin{array}{l}\text { Sorafenib } \\
\text { (400 mg twice } \\
\text { daily) }\end{array}$ & 40 & $\begin{array}{l}40-60 \mathrm{~Gy} / \\
2.0-2.5 \mathrm{~Gy} \text { per } \\
\text { fraction }\end{array}$ & $11 \%$ & $55 \%$ & [40] \\
\hline Phase I & $\begin{array}{l}\text { Sorafenib } \\
\text { (200 mg daily) }\end{array}$ & 24 & $\begin{array}{l}\text { SBRT } \\
\text { (39-54 Gy in } 6 \\
\text { fractions) }\end{array}$ & $\begin{array}{l}\text { DLT at } \\
\text { sorafenib } \\
400 \text { mg daily }\end{array}$ & NA & [41] \\
\hline
\end{tabular}

grade 3 toxicity as hand-foot syndrome, which developed in $17 \%$ of all patients [39]. In a phase II trial of concurrent RT and sorafenib (400 mg twice daily) conducted in 40 patients with advanced HCC, Chen et al. demonstrated a median RT dose of 50 Gy to the liver tumor and a response rate of $55 \%$. However, more than grade 3 hepatic toxicity developed in six patients $(15 \%)$, three of whom died [40]. In a phase I trial to determine the tolerated dose of sorafenib when combined with SBRT in HCC, Dawson et al. observed dose limiting toxicities (DLT) in patients with large tumors treated with SBRT (39-54 Gy in 6 fractions) and sorafenib (400 mg daily) and suggested the use of sequential SBRT followed by sorafenib (200 mg daily) [41]. Though the results have been encouraging, the combination remains highly toxic. Nevertheless, the clinical trial, RTOG 1112, is ongoing to address the issue of whether sequential SBRT and sorafenib is more effective than sorafenib alone (table 4).

RS compounds are still under development. HDAC inhibitors prevent HDACs from removing acetyl groups on histone tails and affects the interaction between chromatin-associated complexes, histone proteins, and DNA molecules. Lu et al. tested the synergism of one of the phenylbutyrate-derived HDAC inhibitors, AR-42 (Arno Therapeutics, Inc., Fairfield, NJ) with RT for HCC. The addition of AR- 42 to RT had a tumor-suppressive effect in up to $82 \%$ of cases. The RS effect was associated with the inhibition of DNA repair and intratumoral Ku70 activity [6]. Aurora kinase inhibitor interrupts accurate cell cycling and reduces genomic stability by interfering with the mitotic kinase Aurora A. Radiation sensitization with VE-465, another Aurora kinase inhibitor, has been achieved in HCC treatment via blockade of histone H3 phosphorylation and disruption of the cell cycle [7]. It has been proposed that the phosphoinositide-3 kinase (PI3K)/serine/threonine-specific protein kinase (Akt) pathway is associated with RT resistance. Liu et al. demonstrated that the RS effect of BKM120 (a pure PI3K inhibitor) on HCC is mediated through the inhibition of Akt activation resulting in apoptosis and impaired DNA damage repair [8]. A novel sorafenib derivative, SC-59, synergizes with RT via targeting SHP-1(SH2 domain-containing phosphatase 1)/STAT3 signaling [9]. Guillot et al. investigated the RS effects of small molecule inhibitors of poly (adenosine diphosphate ribose) polymerases (PARPi) and related these effects to the inhibition of DNA damage repair. Thus, in HCC with a high propensity to DNA damage, PARPi might eradicate the tumor by synergizing with RT [42] (table 3).

With their success in clinical trials, anti-cytotoxic T-lymphocyte-associated antigen 4 and anti-programmed-death-1 antibody-based cancer immunotherapies have come of age [43]. However, the data on RT combined with immunotherapy for HCC is still sparse. In a phase I study of immunotherapy (intratumoral injection of hydroxyapatite $\left[\mathrm{Ca}_{10}\left(\mathrm{PO}_{4}\right)_{6}(\mathrm{OH})_{2}\right] \mathrm{im}$ mune adjuvant three times at one-week intervals after PBT) for patients with locally advanced or recurrent HCC, Abei et al. found transient low-grade fever and less or equal to grade 2 tox- 
icities in seven of nine enrolled patients, and more than 1-year progression-free survival in four patients [44].

\section{Biomarkers}

With the development of more advanced treatment modalities, useful biomarkers are urgently needed for predicting treatment outcome and for selecting patients. However, most of the available biomarkers are prognostic factors, and treatment prediction factors are scarce. AFP is the most widely used biomarker in the diagnosis of HCC and evaluation of its treatment response. Moreover, two biomarkers, namely AFP-L3 and DCP, have been developed for HCC detection and surveillance of at-risk patients [45]. In the SHARP study, baseline plasma levels of AFP and alkaline phosphatase were used as prognostic factors for survival. Among the biomarkers validated in the trial, there were two independent predictors of survival (baseline plasma levels of vascular endothelial growth factor [VEGF] and angiopoietin 2) and two predictors of sorafenib response (hepatocyte growth factor and soluble c-KIT) both with a trend toward increased survival benefit [46].

Two studies addressed the association of angiogenesis factors with RT. Chung et al. compared patients undergoing TACE alone with those undergoing TACE followed by 3D-CRT and noted substantial tumor regression in patients treated with TACE+RT. However, the survival benefit of RT was offset by out-of-field tumor progression. Based on the results of in vitro and in vivo experiments, they proposed that serum VEGF was induced by RT. The up-regulated VEGF resulted in angiogenesis and intra- and extra-hepatic failure outside the RT field [47]. In a phase II study of RT combined with the anti-angiogenesis agent, thalidomide, Ch'ang et al. compared the combined treatment with RT alone and found that the drug suppresses serum levels of fibroblast growth factor, interleukin-6 (IL-6), and tumor necrosis factor- $\alpha$. In multivariate analysis, the significant factors of progression-free survival were baseline levels of serum IL-6 and stem cell-derived factor-1 [48].

The significance of CTC in the peripheral blood has been associated with prognosis in several cancer types [49]. Guo et al. used an optimised negative enrichment and quantitative real time-polymerase chain reaction (qRT-PCR) -based platform for CTC detection in patients with HCC. Intrahepatic lesions in 66 patients received RT. Pretreatment with epithelial cell adhesion molecule (EpCAM), messenger ribonucleic acid (mRNA) and CTC was an independent prognostic factor for disease progression. In the 22 patients with pretreatment and 1-month posttreatment blood samples, six (27.3\%) patients showed increased numbers of CTC, $10(45.4 \%)$ patients had decreased numbers of CTC, and six (27.3\%) patients had no change in CTC status. The tumor progressed in four of the six (66.7\%) patients, with increased CTC numbers after treatment [50] (table 5).

\section{Conclusion}

With the advancement of RT technology, the role of RT in HCC has gradually shifted from palliation to curative ablation. Although improved schemes are still being sought, ablative SBRT dose delivery has achieved favorable local control in over $65 \%$ of cases at one year. Compared to CPTs, SBRT has similar efficacy but slightly higher toxicity. Preclinical and clinical studies have reported encouraging results with targeted radiosensitizers and immunotherapeutic agents. The biomarkers associated with HCC RT include angiogenesis factors and CTC. The combination of radiosensitizers with SBRT, and the appropriate patient selec- 
Table 5. Biomarkers and the clinical use in HCC after radiotherapy

\begin{tabular}{|c|c|c|c|c|c|}
\hline $\begin{array}{l}\text { Sample } \\
\text { type }\end{array}$ & $\begin{array}{l}\text { No. of } \\
\text { patients }\end{array}$ & Assay & $\begin{array}{l}\text { Biomarkers } \\
\text { proposed }\end{array}$ & Comments & References \\
\hline Serum & 42 & $\begin{array}{l}\text { Enzyme- } \\
\text { linked } \\
\text { immunoassay }\end{array}$ & IL-6, SDF-1 & $\begin{array}{l}\text { Baseline IL-6, SDF-1 predicted PFS. } \\
\text { Decreased SDF-1 at 1-month after } \\
\text { RT completion predicted OS. }\end{array}$ & [48] \\
\hline Blood & 22 & $\begin{array}{l}\text { EpCAM mRNA } \\
+ \text { CTC by } \\
\text { qRT-PCR } \\
\text { platform }\end{array}$ & CTC & $\begin{array}{l}\text { Decrease in CTC levels after } \\
\text { treatment that reflected tumor } \\
\text { response. }\end{array}$ & [49] \\
\hline
\end{tabular}

SDF-1=stem cell-derived factor-1; PFS=progression-free survival.

tion using potential biomarkers, might in the future become viable treatment strategies for patients with locally advanced or medically unresectable HCC.

\section{Conflict of Interest Statement}

None declared.

\section{References}

1 Lencioni R, de Baere T, Martin RC, Nutting CW, Narayanan G: Image-guided ablation of malignant liver tumors: Recommendations for clinical validation of novel thermal and non-thermal technologies - a western perspective. Liver Cancer 2015;4:208-214.

2 Lin S, Hoffmann K, Schemmer P: Treatment of hepatocellular carcinoma: a systematic review. Liver Cancer 2012;1:144-158.

3 Bujold A, Massey CA, Kim JJ, Brierley J, Cho C, Wong RK, Dinniwell RE, Kassam Z, Ringash J, Cummings B, Sykes J, Sherman M, Knox JJ, Dawson LA: Sequential phase I and II trials of stereotactic body radiotherapy for locally advanced hepatocellular carcinoma. J Clin Oncol 2013;31:1631-1639.

4 Price TR, Perkins SM, Sandrasegaran K, Henderson MA, Maluccio MA, Zook JE, Tector AJ, Vianna RM, Johnstone PA, Cardenes HR: Evaluation of response after stereotactic body radiotherapy for hepatocellular carcinoma. Cancer 2012;118:3191-3198.

5 Kvols LK: Radiation sensitizers: a selective review of molecules targeting DNA and non-DNA targets. J Nucl Med 2005;46(Suppl 1):187S-190S.

6 Lu YS, Chou CH, Tzen KY, Gao M, Cheng AL, Kulp SK, Cheng JC: Radiosensitizing effect of a phenylbutyrate-derived histone deacetylase inhibitor in hepatocellular carcinoma. Int J Radiat Oncol Biol Phys 2012;83:e181e189.

7 Lin ZZ, Chou CH, Cheng AL, Liu WL, Chia-Hsien Cheng J: Radiosensitization by combining an aurora kinase inhibitor with radiotherapy in hepatocellular carcinoma through cell cycle interruption. Int J Cancer 2014;135:492-501.

8 Liu WL, Gao M, Tzen KY, Tsai CL, Hsu FM, Cheng AL, Cheng JC: Targeting Phosphatidylinositide3-Kinase/Akt pathway by BKM120 for radiosensitization in hepatocellular carcinoma. Oncotarget 2014;5:3662-3672.

9 Huang CY, Tai WT, Hsieh CY, Hsu WM, Lai YJ, Chen LJ, Shiau CW, Chen KF: A sorafenib derivative and novel SHP-1 agonist, SC-59, acts synergistically with radiotherapy in hepatocellular carcinoma cells through inhibition of STAT3. Cancer Lett 2014;349:136-143.

10 Chi KH, Liu SJ, Li CP, Kuo HP, Wang YS, Chao Y, Hsieh SL: Combination of conformal radiotherapy and intratumoral injection of adoptive dendritic cell immunotherapy in refractory hepatoma. J Immunother 2005;28:129-135.

11 Raoul JL, Park JW, Kang YK, Finn RS, Kim JS, Yeo W, Polite BN, Chao Y, Walters I, Baudelet C, Lencioni R: Using modified recist and alpha-fetoprotein levels to assess treatment benefit in hepatocellular carcinoma. Liver Cancer 2014;3:439-450.

12 Toyoda H, Kumada T, Tada T, Sone Y, Kaneoka Y, Maeda A: Tumor markers for hepatocellular carcinoma: Simple and significant predictors of outcome in patients with hcc. Liver Cancer 2015;4:126-136.

13 Jackson A, Ten Haken RK, Robertson JM, Kessler ML, Kutcher GJ, Lawrence TS: Analysis of clinical complication data for radiation hepatitis using a parallel architecture model. Int J Radiat Oncol Biol Phys 1995;31:883-891. 
14 Cheng JC, Liu HS, Wu JK, Chung HW, Jan GJ: Inclusion of biological factors in parallel-architecture normaltissue complication probability model for radiation-induced liver disease. Int J Radiat Oncol Biol Phys 2005;62:1150-1156.

15 Mornex F, Girard N, Beziat C, Kubas A, Khodri M, Trepo C, Merle P: Feasibility and efficacy of high-dose three-dimensional-conformal radiotherapy in cirrhotic patients with small-size hepatocellular carcinoma non-eligible for curative therapies - mature results of the French Phase II RFT-1 trial. Int J Radiat Oncol Biol Phys, 2006;66:1152-1158.

16 Seong J, Lee IJ, Shim SJ, Lim H, Kim TH, Kim JH, Jang HS, Kim MS, Chie EK, Kim JH, Nam TK, Lee HS, Han CJ: A multicenter retrospective cohort study of practice patterns and clinical outcome on radiotherapy for hepatocellular carcinoma in Korea. Liver Int 2009;29:147-152.

17 Liu MT, Li SH, Chu TC, Hsieh CY, Wang AY, Chang TH, Pi CP, Huang CC, Lin JP: Three-dimensional conformal radiation therapy for unresectable hepatocellular carcinoma patients who had failed with or were unsuited for transcatheter arterial chemoembolization. Jpn J Clin Oncol 2004;34:532-539.

18 Blomgren H, Lax I, Näslund I, Svanström R: Stereotactic high dose fraction radiation therapy of extracranial tumors using an accelerator. Clinical experience of the first thirty-one patients. Acta Oncol 1995;34:861-870.

19 Choi BO, Jang HS, Kang KM, Lee SW, Kang YN, Chai GY, Choi IB: Fractionated stereotactic radiotherapy in patients with primary hepatocellular carcinoma. Jpn J Clin Oncol 2006;36:154-158.

20 Kwon JH, Bae SH, Kim JY, Choi BO, Jang HS, Jang JW, Choi JY, Yoon SK, Chung KW: Long-term effect of stereotactic body radiation therapy for primary hepatocellular carcinoma ineligible for local ablation therapy or surgical resection. Stereotactic radiotherapy for liver cancer. BMC Cancer 2010;10:475.

21 Seo YS, Kim MS, Yoo SY, Cho CK, Choi CW, Kim JH, Han CJ, Park SC, Lee BH, Kim YH, Lee DH: Preliminary result of stereotactic body radiotherapy as a local salvage treatment for inoperable hepatocellular carcinoma. J Surg Oncol 2010;102:209-214.

22 Louis C, Dewas S, Mirabel X, Lacornerie T, Adenis A, Bonodeau F, Lartigau E: Stereotactic radiotherapy of hepatocellular carcinoma: preliminary results. Technol Cancer Res Treat 2010;9:479-487.

23 Andolino DL, Johnson CS, Maluccio M, Kwo P, Tector AJ, Zook J, Johnstone PA, Cardenes HR: Stereotactic body radiotherapy for primary hepatocellular carcinoma. Int J Radiat Oncol Biol Phys 2011;81:e447e 453.

24 Huang WY, Jen YM, Lee MS, Chang LP, Chen CM, Ko KH, Lin KT, Lin JC, Chao HL, Lin CS, Su YF, Fan CY, Chang YW: Stereotactic body radiation therapy in recurrent hepatocellular carcinoma. Int J Radiat Oncol Biol Phys 2012;84:355-361.

25 Bae SH, Kim MS, Cho CK, Kim KB, Lee DH, Han CJ, Park SC, Kim YH: Feasibility and efficacy of stereotactic ablative radiotherapy for Barcelona Clinic Liver Cancer-C stage hepatocellular carcinoma. J Korean Med Sci 2013;28:213-219.

26 Méndez Romero A, Wunderink W, Hussain SM, De Pooter JA, Heijmen BJ, Nowak PC, Nuyttens JJ, Brandwijk RP, Verhoef C, Ijzermans JN, Levendag PC: Stereotactic body radiation therapy for primary and metastatic liver tumors: A single institution phase i-ii study. Acta Oncol 2006;45:831-837.

27 Tse RV, Hawkins M, Lockwood G, Kim JJ, Cummings B, Knox J, Sherman M, Dawson LA: Phase I study of individualized stereotactic body radiotherapy for hepatocellular carcinoma and intrahepatic cholangiocarcinoma. J Clin Oncol 2008;26:657-664.

28 Fukumitsu N, Sugahara S, Nakayama H, Fukuda K, Mizumoto M, Abei M, Shoda J, Thono E, Tsuboi K, Tokuuye K: A prospective study of hypofractionated proton beam therapy for patients with hepatocellular carcinoma. Int J Radiat Oncol Biol Phys 2009;74:831-836.

29 Bush DA, Kayali Z, Grove R, Slater JD: The safety and efficacy of high-dose proton beam radiotherapy for hepatocellular carcinoma: a phase 2 prospective trial. Cancer 2011;117:3053-3059.

30 Kato H, Tsujii H, Miyamoto T, Mizoe JE, Kamada T, Tsuji H, Yamada S, Kandatsu S, Yoshikawa K, Obata T, Ezawa H, Morita S, Tomizawa M, Morimoto N, Fujita J, Ohto M, Liver Cancer Working Group: Results of the first prospective study of carbon ion radiotherapy for hepatocellular carcinoma with liver cirrhosis. Int J Radiat Oncol Biol Phys 2004;59:1468-1476.

31 Qi WX, Fu S, Zhang Q, Guo XM: Charged particle therapy versus photon therapy for patients with hepatocellular carcinoma: a systematic review and meta-analysis. Radiother Oncol 2015;114:289-295.

32 Heidelberger C, Griesbach L, Cruz O, Schnitzer RJ, Grunberg E: Fluorinated pyrimidines. VI. Effects of 5-fluorouridine and 5-fluoro-2'-deoxyuridine on transplanted tumors. Proc Soc Exp Biol Med 1958;97:470475.

33 Dawson LA, McGinn CJ, Normolle D, Ten Haken RK, Walker S, Ensminger W, Lawrence TS: Escalated focal liver radiation and concurrent hepatic artery fluorodeoxyuridine for unresectable intrahepatic malignancies. J Clin Oncol 2000;18:2210-2218.

34 Liu L, Cao Y, Chen C, Zhang X, McNabola A, Wilkie D, Wilhelm S, Lynch M, Carter C: Sorafenib blocks the RAF/MEK/ERK pathway, inhibits tumor angiogenesis, and induces tumor cell apoptosis in hepatocellular carcinoma model PLC/PRF/5. Cancer Res 2006;66:11851-11858.

35 Llovet JM, Ricci S, Mazzaferro V, Hilgard P, Gane E, Blanc JF, de Oliveira AC, Santoro A, Raoul JL, Forner A, Schwartz M, Porta C, Zeuzem S, Bolondi L, Greten TF, Galle PR, Seitz JF, Borbath I, Häussinger D, Giannaris T, Shan M, Moscovici M, Voliotis D, Bruix J, SHARP Investigators Study Group: Sorafenib in advanced hepatocellular carcinoma. N Engl J Med 2008;359:378-390. 
36 Cheng AL, Kang YK, Chen Z, Tsao CJ, Qin S, Kim JS, Luo R, Feng J, Ye S, Yang TS, Xu J, Sun Y, Liang H, Liu J, Wang J, Tak WY, Pan H, Burock K, Zou J, Voliotis D, Guan Z: Efficacy and safety of sorafenib in patients in the Asia-Pacific region with advanced hepatocellular carcinoma: a phase III randomised, double-blind, placebo-controlled trial. Lancet Oncol 2009;10:25-34.

37 Huang CY, Lin CS, Tai WT, Hsieh CY, Shiau CW, Cheng AL, Chen KF: Sorafenib enhances radiation-induced apoptosis in hepatocellular carcinoma by inhibiting STAT3. Int J Radiat Oncol Biol Phys 2013;86:456-462.

38 Yu W, Gu K, Yu Z, Yuan D, He M, Ma N, Lai S, Zhao J, Ren Z, Zhang X, Shao C, Jiang GL: Sorafenib potentiates irradiation effect in hepatocellular carcinoma in vitro and in vivo. Cancer Lett 2013;329:109-117.

39 Cha J, Seong J, Lee IJ, Kim JW, Han KH: Feasibility of sorafenib combined with local radiotherapy in advanced hepatocellular carcinoma. Yonsei Med J 2013;54:1178-1185.

40 Chen SW, Lin LC, Kuo YC, Liang JA, Kuo CC, Chiou JF: Phase 2 study of combined sorafenib and radiation therapy in patients with advanced hepatocellular carcinoma. Int J Radiat Oncol Biol Phys 2014;88:10411047.

41 Dawson LA, Brade A, Cho C, et al: Phase i study of sorafenib and sbrt for advanced hepatocellular carcinoma. International Journal of Radiation Oncology · Biology · Physics 2011;84:S10-S11.

42 Muñoz-Gámez JA, Quiles-Pérez R, Ruiz-Extremera A, Martín-Álvarez AB, Sanjuan-Nuñez L, Carazo A, León J, Oliver FJ, Salmerón J: Inhibition of poly (ADP-ribose) polymerase-1 enhances doxorubicin activity against liver cancer cells. Cancer Lett 2011;301:47-56.

43 Mellman I, Coukos G, Dranoff G: Cancer immunotherapy comes of age. Nature 2011;480:480-489.

44 Abei M, Okumura T, Fukuda K, Hashimoto T, Araki M, Ishige K, Hyodo I, Kanemoto A, Numajiri H, Mizumoto M, Sakae T, Sakurai H, Zenkoh J, Ariungerel G, Sogo Y, Ito A, Ohno T, Tsuboi K: A phase I study on combined therapy with proton-beam radiotherapy and in situ tumor vaccination for locally advanced recurrent hepatocellular carcinoma. Radiat Oncol 2013;8:239.

45 Lai Q, Melandro F, Pinheiro RS, et al: Alpha-fetoprotein and novel tumor biomarkers as predictors of hepatocellular carcinoma recurrence after surgery: A brilliant star raises again. Int J Hepatol 2012:893103.

46 Llovet JM, Peña CE, Lathia CD, Shan M, Meinhardt G, Bruix J, SHARP Investigators Study Group: Plasma biomarkers as predictors of outcome in patients with advanced hepatocellular carcinoma. Clin Cancer Res 2012;18:2290-2300.

47 Chung YL, Jian JJ, Cheng SH, Tsai SY, Chuang VP, Soong T, Lin YM, Horng CF: Sublethal irradiation induces vascular endothelial growth factor and promotes growth of hepatoma cells: implications for radiotherapy of hepatocellular carcinoma. Clin Cancer Res 2006;12:2706-2715.

48 Ch'ang HJ, Hsu C, Chen CH, Chang YH, Chang JS, Chen LT: Phase II study of concomitant thalidomide during radiotherapy for hepatocellular carcinoma. Int J Radiat Oncol Biol Phys 2012;82:817-825.

49 Alix-Panabières C, Pantel K: Challenges in circulating tumour cell research. Nat Rev Cancer 2014;14:623631.

50 Guo W, Yang XR, Sun YF, Shen MN, Ma XL, Wu J, Zhang CY, Zhou Y, Xu Y, Hu B, Zhang X, Zhou J, Fan J: Clinical significance of EpCAM mRNA-positive circulating tumor cells in hepatocellular carcinoma by an optimized negative enrichment and qRT-PCR-based platform. Clin Cancer Res 2014;20:4794-4805. 